\title{
Currículo, escola e letramento: o que isso tem a ver com a formação do cidadão?
}

\author{
Ezequiel Ferreira Barbosa ${ }^{1}$ \\ Maria Candia Müller ${ }^{2}$
}

\section{Resumo.}

Este trabalho tem por objetivo apresentar algumas considerações sobre currículo e sua importância para a adoção de uma prática educativa que rompa com velhos paradigmas, tendo em vista que o conceito adotado e praticado nas escolas tem se tornado um empecilho para a realização de um trabalho que leve os alunos a serem agentes da sua própria aprendizagem e, consequentemente, cidadãos conscientes, inseridos num mundo em constante transformação. Aborda ainda a questão do letramento como prática cotidiana nas escolas, tendo como reflexo a formação para o exercício da cidadania. Procura apresentar também que o domínio das habilidades linguísticas é uma condição, sem a qual, a aprendizagem fica comprometida e que essas habilidades, que vão muito além do simples ato codificar e decodificar palavras, é uma tarefa da responsabilidade de todos os professores, não apenas dos de língua materna.

Palavras-Chave: currículo; escola; letramento; habilidades linguísticas.

\section{Abstract.}

This paper aims to present some considerations about curriculum and its importance to the adoption of an educational practice that breaks with old paradigms, considering that the concept adopted and practiced in schools has become a hindrance to the realization of a work that takes students to be agents of their own learning and, consequently, conscious citizen entered in a world in constant transformation. It also approach the issue of literacy as a daily practice in schools, reflecting the training for citizenship. It also seeks to show that the area of language skills is a condition without which learning is compromised and that these skills that go far beyond the simple act encode and decode words and a task that is the responsibility of all teachers, not just the mother language.

Key words: curriculum; school; literacy; language skills.

\section{Algumas considerações sobre o currículo}

O discurso estabelecido na e pela sociedade é de que é a partir de uma educação de qualidade que poderemos resolver os nossos problemas sociais. Assim, a educação sempre foi motivo de discussões e pesquisas no que se refere a sua função.

A Lei de Diretrizes e Bases da Educação Nacional (LDB) em seu artigo $1^{\circ}$ preconiza que “a educação abrange os processos formativos que se desenvolvem na vida familiar, na

\footnotetext{
${ }^{1}$ Professor do Instituto Federal de Rondônia e mestrando do programa de Mestrado Profissional em Educação Escolar - MEPE da Universidade Federal de Rondônia - UNIR. ezequielfrata@ifro.edu.br

2 Doutora em Educação pela Universidade Estadual de Campinas - UNICAMP, professora da Fundação Universidade Federal de Rondônia (UNIR), Departamento Acadêmico de Ciências da Educação, Campus de Vilhena - maria.candida@unir.br
} 
convivência humana, no trabalho, nas instituições de ensino e pesquisa, nos movimentos sociais e organizações da sociedade civil e nas manifestações culturais". No entanto, a ideia impregnada no imaginário de muitas pessoas é a de que a escola é a única responsável pela formação do cidadão e delega exclusivamente a ela essa responsabilidade, talvez porque nenhuma outra forma de aparelhamento tenha sido capaz equiparar-se ou de substituí-la.

A escola é uma instituição social que tem como objetivo o desenvolvimento das potencialidades dos alunos por meio da aprendizagem dos conteúdos que devem acontecer de maneira contextualizada, desenvolvendo neles a capacidade de tornarem-se cidadãos participativos na sociedade em que vivem.

A educação institucionalizada deve ser vista dentro de uma totalidade, envolvendo não só o que acontece na escola, mas em todos os ambientes e relações que envolvem o ser humano. As habilidades e conhecimento são preocupações mais da educação escolar do que de outras instituições sociais. Os valores e atitudes que também são fundamentais à educação, tornam-se raros e passam despercebidos tanto na família quanto na sociedade, podendo ser considerados como um dos principais elementos do fracasso da e na escola e da precariedade da cidadania nos dias atuais.

Para Sacristán (2000, p. 17),

(...) todas as finalidades que se atribuem e são destinadas implícita ou explicitamente à instituição escolar, de socialização, de formação, de segregação ou de integração social, etc., acabam necessariamente tendo um reflexo nos objetivos que orientam todo o currículo, na seleção de componentes do mesmo, desembocam numa divisão especialmente ponderada entre diferentes parcelas curriculares e nas próprias atividades metodológicas às quais dá lugar. Por isso, o interesse pelos problemas relacionados com o currículo não é senão uma consequência da consciência de que é por meio dele que se realizam basicamente as funções da escola como instituição.

Embora a escola não deva ser vista isoladamente, Nóvoa (2007) afirma que um excesso de tarefas foi lançado para dentro dela, o que tem levado a uma dispersão excessiva e a uma dificuldade de definir prioridades, incapazes de um foco, de definir estratégias claras. Segundo o autor, tudo é importante, desde que não se esqueça de que a prioridades primeira dos docentes é a aprendizagem dos alunos.

A educação e o ato de educar é muito mais que transmitir conhecimentos, isso porque a aprendizagem não acontece pelo simples fato de receber conhecimentos, mas em transformar conhecimentos em aprendizagem que faça sentido para a vida dos indivíduos em seus mais diversos contextos sociais, tornando o homem consciente de si e de sua responsabilidade com os outros. Para Nóvoa (2007, p. 6), 
A pedagogia tradicional era baseada nos conhecimentos e na transmissão dos conhecimentos. A grande ruptura provocada pela pedagogia moderna foi colocar os alunos no centro do sistema. Mas a pedagogia moderna precisa ser reinventada na sociedade contemporânea. Não se trata de centrar na escola nem nos conhecimentos, como advogava a pedagogia tradicional, nem nos alunos, como advogava a pedagogia moderna, mas, sim, na aprendizagem. É evidente que a aprendizagem implica alunos. A aprendizagem implica uma pessoa, um aluno concreto, implica o seu desenvolvimento, o seu bem-estar. Mas uma coisa é dizer que nosso objetivo está centrado no aluno e outra coisa na aprendizagem do aluno. E definirmos isso como nossa prioridade no trabalho dentro das escolas.

Entretanto, no espaço escolar, o que se percebe como educação em geral ainda é uma visão bastante tradicional do que é educar. Muitas escolas mantêm-se resistentes às mudanças que afetam a sociedade e continuam oferecendo uma educação semelhante àquela do passado.

Não é novidade para quem conhece a rotina escolar, que adota-se um discurso inovador, progressista, no entanto, uma prática avessa ao discurso. É necessário estabelecer uma discussão e reflexão sobre a prática escolar e como transformá-la de modo a atender às exigências do mundo moderno.

A função da escola de hoje é complexa, ampla e diversificada. Para acompanhar as contínuas transformações sociais, a escola precisa estabelecer conexão entre o que o aluno aprende nela e o que ele faz fora dela.

Se objetivo da escola é, em princípio, oferecer formação para que seus alunos saiam da condição em que se encontram e consigam superar seus limites e os limites impostos pelas diferenças sociais que se impõem como barreira para sua mobilidade social, é necessário pensar um currículo, não apenas como uma estrutura em que é apresentada uma relação de conteúdos, com objetivos e metas a serem alcançadas, é necessário pensar o currículo, segundo Sacristán (2000, pp. 15-16), como

(...) uma práxis antes que um objeto estático emanado de um modelo coerente de pensar a educação ou as aprendizagens necessárias das crianças e dos jovens, que tampouco se esgota na parte explícita do projeto de socialização cultural nas escolas. É uma prática, expressão, da função socializadora e cultural que determinada instituição tem, que reagrupa em torno dele uma série de subsistemas ou práticas diversas, entre as quais se encontra a prática pedagógica desenvolvida em instituições escolares que comumente chamamos ensino. É uma prática que se expressa em comportamentos práticos diversos. O currículo, como projeto baseado num plano construído e ordenado, relaciona a conexão entre determinados princípios e uma realização dos mesmos, algo que se há de comprovar e que nessa expressão prática concretiza seu valor. Uma prática na qual se estabelece um diálogo, por assim dizer, entre agentes sociais, elementos técnicos, alunos que reagem frente a ele, professores que o modelam, etc. Desenvolver esta acepção do currículo como âmbito prático tem o atrativo de poder ordenar em torno deste discurso as funções que cumpre e o modo como as realiza, estudando-o processualmente: se expressa numa prática e ganha significado dentro de uma prática de algum modo prévio e que não é função apenas do currículo, mas de outros determinantes. É o contexto da prática, ao mesmo tempo que é contextualizado por ela. 
O currículo deve estabelecer uma relação entre o que o aluno aprende e o que ele vivencia, permitindo que os conhecimentos adquiridos melhorem sua atuação na vida cotidiana. A metodologia aplicada deve propiciar ao aluno condições de fazer ligações entre o que aprende em sala de aula e o que exercita na prática diária. De acordo com Nóvoa (2007, pp 6,7),

A aprendizagem necessita também dos conhecimentos. E os conhecimentos, é preciso
reconhecer, durante algum tempo foram uma espécie de paradigma ausente de muitas
práticas pedagógicas. A melhor expressão que define isso é "aprender a aprender", a
ideia de que se poderia aprender num vazio de conhecimentos. É preciso insistir na
ideia de centrar o foco na aprendizagem e que essa aprendizagem implica em alunos e
conhecimentos. Ela não se faz sem pessoas e uma referência às suas subjetividades, sem
referências aos seus contextos sociais, suas sociabilidades. Mas ela também não se faz
sem conhecimentos e sem a aprendizagem desses conhecimentos, sem o domínio das
ferramentas do saber que são essenciais para as sociedades do século XXI, que todos
querem ver definidas como sociedades do conhecimento.

"Eis o grande desafio da escola, fazer do ambiente escolar um meio que favoreça o aprendizado, onde a escola deixe de ser apenas um ponto de encontro e passe a ser, além disso, encontro com o saber com descobertas de forma prazerosa e funcional. " (LIBÂNEO, 2005, p.117). Várias foram e são as tentativas de mudança a partir da implantação de novas tendências e propostas, em sua grande maioria trazidas de fora do país, e que foram tidas como a salvação da educação brasileira, no entanto, "não basta estabelecer e difundir um determinado discurso ideológico e técnico-pedagógico para que se mude, embora se materialize inclusive num plano estruturado, embora seja condição prévia e necessária" (Sacristán, 2000, p. 29), é preciso melhorar as práticas pedagógicas nas quais a aprendizagem se realiza.

Antes e adotar essa ou aquela tendência ou metodologia para a formação do cidadão e sua inserção na sociedade, é preciso entender como a escola tem desenvolvido seu papel frente a uma sociedade cada vez mais exigente e que requer pessoas capazes de transitar entre os vários conhecimentos.

É preciso que se tenha clara a concepção do que é ensinar e do que é aprender. Para se entender essas concepções, portanto é preciso entender a concepção de currículo adotada pela escola e como são ou deveriam ser construídos para a garantia de uma prática educativa relevante e que garanta a sua função social na formação do indivíduo.

Segundo Sacristán (2000, p. 15), “quando definimos o currículo estamos descrevendo a concretização das funções da própria escola e a forma particular de enfocá-las num momento histórico e social determinado, para um nível ou modalidade de educação, numa trama institucional".

Assim, adota-se uma prática de ensino que seja relevante para a aprendizagem no contexto escolar, uma prática que reflete a vida social de seus alunos. 
Para Coll (1987, p. 45), o currículo é

o projeto que preside as atividades educativas escolares, define suas intenções e proporciona guias de ação adequadas e úteis para os professores, que são diretamente responsáveis pela sua execução. Para isso, o currículo proporciona informações concretas sobre que ensinar, quando ensinar, como ensinar e que, como e quando avaliar.

É comum nas escolas referir-se ao currículo como um programa de conteúdos e atividades planejadas, com sequência e ordem metodológica como são apresentados nos manuais didáticos ou num guia do professor, talvez pela comodidade ou pela falta de conhecimento de como elaborar um currículo que não contemple apenas a transmissão de conteúdos escolares, mas suas relações com o cotidiano fora do ambiente escolar.

Por mais que se tenha proposto uma nova forma de estrutura e apresentação dos conhecimentos, ainda persistem práticas de ensino vinculadas a uma abordagem tradicional de educação, de acordo com Mizukami (1986), centrado no professor em que o aluno apenas executa o que lhe é determinado. A relação professor-aluno é sempre baseada na verticalidade, o professor decide qual conteúdo, a metodologia a forma de avaliação e a que objetivos serão encaminhados, ou seja, o professor decide tudo, cabendo ao aluno a tarefa de reproduzir o que foi transmitido.

Nessa abordagem o aluno é um receptor passivo e se não for capaz de reproduzir o que lhe foi repassado é considerado incapaz de prosseguir em sua vida escolar, amargando uma reprovação, resultado na maioria das vezes justificado pela aplicação de uma prova que tem um fim em si mesma e o assunto continua, mesmo o professor tendo consciência do fato de o aluno não ter se apropriado do conhecimento.

Assim, o conhecimento é visto como sendo adquirido através da capacidade de acumular ou armazenar informações, desconsiderando sua capacidade na elaboração e aquisição do conhecimento, já que considera a escola um lugar onde se realizam a educação. Nesse modelo de escola, o professor limita-se a fornecer informações, não propiciando a transformação das informações em conhecimento capaz de transformar o indivíduo. "É um ensino caracterizado por se preocupar mais com a variedade e quantidade de noções/conceitos/informações que com a formação do pensamento reflexivo." (MIZUKAMI, 1986, p. 14).

A concepção de currículo, desvinculada da realidade em que cada escola está localizada em nada contribui para a formação do cidadão, uma vez que não considera a realidade em que seus alunos estão inseridos, fazendo com que fiquem desinteressados, interferindo de forma negativa no seu processo de aprendizagem. De acordo com Sacristán (2000, p. 20), 
O grau e tipo de saber que os indivíduos logram nas instituições escolares, sancionado e legitimado por elas, têm consequências no nível de seu desenvolvimento pessoal, em suas relações sociais e, mais concretamente, no status que esse indivíduo possa conseguir dentro da estrutura profissional de seu contexto.

Segundo Lima (2007, p.20),

Um currículo para a formação humana introduz sempre novos conhecimentos, não se limita aos conhecimentos relacionados às vivências do aluno, às realidades regionais, ou com base no assim chamado conhecimento do cotidiano. É importante alertar para a diferença entre um currículo que parte do cotidiano e aí se esgota e um currículo que engloba em si mesmo não apenas a aplicabilidade do conhecimento à realidade cotidiana vivida por cada grupo social, mas entende que conhecimento formal traz outras dimensões ao desenvolvimento humano, além do "uso prático". Há, portanto, uma diferença entre partir ou utilizar metodologicamente a experiência cultural do aluno como caminho para ampliação da experiência humana na escola e definir como currículo a experiência cultural do aluno.

\section{Currículo como elemento norteador das práticas de letramento}

As transformações pelas quais a sociedade tem passado exige cada vez mais indivíduos capazes de lidar com as informações de maneira crítica, por isso é necessária uma formação que atenda a essa demanda e a leitura exerce um papel preponderante no processo de construção do conhecimento. Segundo Sacristán (2000, p. 20),

Numa sociedade avançada, o conhecimento tem um papel relevante e progressivamente cada vez mais decisivo. Uma escola 'sem conteúdos' culturais é uma proposta irreal, além de descomprometida. O conhecimento, e principalmente a legitimação social de sua possessão que as instituições proporcionam, é um meio que possibilita ou não a participação nos processos culturais e econômicos da sociedade, ou seja, ela facilita num determinado grau e numa direção.

$\mathrm{Na}$ escola, a leitura é o elo de ligação para o desenvolvimento de competências e habilidades para a formação de alunos capazes de aprender de forma autônoma ao longo de suas vidas.

Segundo os Parâmetros Curriculares Nacionais (BRASIL, 1997, p. 21),

O domínio da língua tem estreita relação com a possibilidade de plena participação social, pois é por meio dela que o homem se comunica, tem acesso à informação, expressa e defende pontos de vista, partilha ou constrói visões de mundo, produz conhecimento. Assim, um projeto educativo comprometido com a democratização social e cultural atribui à escola a função e a responsabilidade de garantir a todos os seus alunos o acesso aos saberes linguísticos necessários para o exercício da cidadania, direito inalienável de todos. 
Cada componente curricular traz conhecimentos que utilizam os mais diversos gêneros textuais ${ }^{3}$ para os quais é necessário usar estratégias específicas de leitura para a produção de sentidos a partir de conhecimentos prévios de mundo, linguísticos, textuais e discursivos para que os alunos saibam transitar através deles a fim de concretizarem suas aprendizagens garantindo seu desenvolvimento enquanto sujeito social.

Dessa forma, o currículo escolar precisa ser uma práxis de caráter unificador cujas dinâmicas de ensino de cada disciplina tornem-se significativamente complementares permeados pelos saberes linguísticos necessários para a aprendizagem.

O domínio das competências linguísticas é uma condição, sem a qual a aprendizagem fica comprometida, competências linguísticas que vão muito além do simples ato codificar e decodificar palavras. Por isso, "o debate em torno da Educação Linguística - o ensino da leitura, da redação, dos usos, do saber sobre a língua e dos valores que se constituem sobre ela - ganhou novos contornos com a introdução, no campo da educação, do conceito de letramento" (BRITTO, 2003, p. 9)

O termo letramento, segundo Soares (2009), é uma palavra incorporada ao vocabulário da Educação e das Ciências Linguísticas na segunda metade dos anos 80 do século passado. O surgimento de uma palavra ou sua ressignificação emergem de novos fatos, novas ideias, novas maneiras de compreender os fenômenos. É o que acontecia naquele momento, o termo alfabetizado, compreendido como aquele que sabe codificar e decodificar, já não atendia às demandas sociais, era necessário então o uso de um termo que representasse a capacidade de ler e escrever que ultrapassasse o domínio do sistema alfabético e ortográfico, nível de aprendizagem da língua escrita perseguido, tradicionalmente, pelo processo de alfabetização.

Para Tfouni (2010, p. 22), “ a necessidade de se começar a falar em letramento surgiu [...] da tomada de consciência que se deu, principalmente entre os linguistas, de que havia alguma coisa além da alfabetização, que era mais ampla, e até determinante desta."

Letramento, no entanto é considerado por alguns autores, mais que o domínio da leitura e da escrita, isto é, alfabetização. Marcuschi (2010, p. 25) afirma que "letrado é o indivíduo que participa de forma significativamente de eventos de letramento e não apenas aquele que faz uso formal da escrita".

Embora a "estrita relação entre letramento e escolarização controla mais que expande o conceito de letramento"(SOARES, 2009, p. 85) (grifos da autora), neste artigo o termo será

\footnotetext{
${ }^{3}$ Segundo Marcuschi (2010) os gêneros textuais são fenômenos históricos, profundamente vinculados à vida cultural e social, portanto, são entidades sociodiscursivas e formas de ação social em qualquer situação comunicativa.
} 
usado no sentido de escolarização da leitura e da escrita, ou seja, "-o resultado da ação de ensinar ou de aprender a ler e escrever: o estado da ação que adquire um grupo social ou indivíduo como consequência de ter se apropriado da escrita" (SOARES, 2009, p.18,), uma vez que estamos tratando da necessidade do domínio da leitura e da escrita como instrumento básico e norteador da aprendizagem e dos resultados escolares e de sistemas de avaliação em larga escala. ${ }^{4}$

No Brasil, embora $97,6 \%{ }^{5}$ das crianças e adolescentes entre 7 e 14 anos estejam matriculados na escola, os resultados da proficiência em leitura têm alcançado níveis insatisfatórios em relação aos anos de escolaridade dos alunos, tanto nos anos iniciais, quanto nos finais da educação básica. A escola tem falhado então em sua função que, segundo os PCNs de Língua Portuguesa (BRASIL, 1997, p. 26), é a de "viabilizar o acesso do aluno ao universo dos textos que circulam socialmente, ensinar a produzi-los e a interpretá-los”.

A escola, em geral, costuma trabalhar com textos que não existem fora dela, são textos descontextualizados que pouco contribuem para o desenvolvimento da competência discursiva dos alunos, incapazes de provocar nos alunos a compreensão das múltiplas funções sociais do texto, o que gera um grande número de pessoas ditas alfabetizadas, mas que não alcançam um nível satisfatório de letramento, "entendido como condição de quem interage com diferentes discursos, saberes e comportamentos articulados em função da cultura escrita. " (BRITTO, 2003, p. 43).

O grande problema em torno desta questão talvez seja o fato de que frequentemente quando se fala de educação linguística, a responsabilidade recaia sobre os professores da disciplina de Língua Portuguesa.

A forma como se organiza a cultura escolar, fortemente disciplinarizada e sustentada em um conjunto de conteúdos fixos bastante estabelecido, tem sido um dos aspectos que mais dificultam o avanço da reflexão pedagógica na educação contemporânea, em especial no que diz respeito ao trabalho com leitura e escrita. (BRITTO, 2003 p. 44)

A educação linguística, quando tratada de forma disciplinarizada, acaba se restringindo a questões de normas e regras, pouco se considerando as questões relativas à produção e circulação do conhecimento.

Considerar o conceito de letramento na escola, além da disciplina de Língua Portuguesa implicaria, de acordo com Britto (2003, p.13), em

deslocar as questões do ensino da escrita das preocupações normativas e de formalidade para os processos de organização dos discursos, das áreas do saber e do

\footnotetext{
${ }^{4}$ São as avaliações externas, cujos objetivos e procedimentos são diferenciados das avaliações realizadas pelos professores nas escolas e são aplicadas de forma padronizada para um grande número de pessoas.

${ }^{5}$ Dado disponível em: http://www.unicef.org/brazil/pt/media_14931.htm
} 
domínio dos recursos da escrita para organizar o pensamento e intervir no espaço social, o que implicaria pensar o ensino da escrita e da leitura além do espaço em que tradicionalmente ele tem sido pensado, isto é, a disciplina de Língua Portuguesa.

Assim caberia à escola pensar um currículo que desloque-se do professor e do conteúdo de cada disciplina isolada, que seja baseado nas competências a serem desenvolvidas e nos objetivos pretendidos para a formação dos alunos, que considere a interdisciplinaridade dos conteúdos e o mundo real, integral e complexo, diferente de uma abordagem tradicional, com uma formação fragmentada e simplificadora da realidade.

Para isso, seria necessário a adoção do currículo não apenas como um conceito, mas como uma forma de organizar as práticas educativas, levando em conta as experiências humanas dos sujeitos envolvidos no processo de aprendizagem e as ações pedagógicas mais adequadas para promovê-la. "Se o currículo, evidentemente, é algo que se constrói, seus conteúdos e suas formas últimas não podem ser indiferentes aos contextos nos quais se configura". (SACRISTÁN, 2000 p.21) A não fragmentação dos saberes é pois uma forma de todos assumirem a responsabilidade pela formação de alunos capazes de se apropriar do conhecimento através da leitura de forma autônoma, já que em todas as disciplinas o nível de letramento interfere diretamente na aprendizagem dos conteúdos trabalhados.

Para Guedes (2006, pp.67,68),

(...) qualquer aula pressupõe a leitura como forma de processamento pessoal e metódico, no ritmo individual de cada um, das informações e das relações com que construir o saber e com que constituir a percepção crítica, que só se forma num contato pessoal refletido com posições confrontantes. Por isso o professor de português não vai de forma genérica ensinar a ler, não será professor de interpretação de texto. A tentativa de atribuir-lhe a tarefa de fornecer instrumentos para que os alunos consigam compreender textos de história, de ciências, do que quer que seja, baseia-se no equívoco de que ler é uma técnica de decodificação do texto, na errônea presunção de que todo sentido do texto está contido nas palavras e frases que o compõem, negligenciando o conjunto das informações prévias, os sentidos paroquiais das expressões no contexto de cada disciplina e desconsiderando que mesmo as palavras não tem o mesmo sentido, que eles variam de acordo com o tema geral que está vinculado o texto que elas compõem. A cultura letrada é o referencial de toda a escola, nesse sentido a aula de (...) qualquer outra disciplina que a escola inventar, só faz sentido se for dada por um leitor para leitores.

Assim, todo professor, antes de ser um agente de letramento precisa ser um sujeito letrado. Toda discussão proposta no texto, em nada faz sentido se o professor não for um sujeito letrado, que seja capaz de transitar entre os mais diversos gêneros textuais, que tenha uma formação que capacite para ser um agente letrador. 


\section{Para Concluir}

A escola, no contexto contemporâneo, passa por uma série de transformações no que diz respeito à sua missão enquanto instituição social formadora de cidadãos. Cobra-se cada vez mais que ela exerça o papel de proporcionar aos alunos a possibilidade de mobilidade social dentro de um contexto onde os papeis na sociedade são determinados pela capacidade de relacionar-se com o outro e com o mundo de um modo geral através de um posicionamento crítico frente às realidades cotidianas. No contexto escolar, no entanto, ainda encontram-se práticas engessadas, descontextualizadas, como se as práticas sociais fossem desvinculadas da realidade dos alunos. A competência comunicativa é o elo de ligação entre o indivíduo e o mundo e para isso é importante que a escola realize um trabalho fundamental para que o aluno amplie suas habilidades e que adote uma prática de letramento que vá muito além de codificar e decodificar palavras ou sentenças, mas uma prática que possibilite aos alunos transitarem pelos mais diversos contextos, dando lhes o direito ao exercício da cidadania.

O cumprimento de sua missão, no entanto, passa necessariamente pela revisão dos conceitos adotados de currículo, deixando de lado velhas práticas conservadoras e adotando seu conceito como construção social que preencha a escolaridade dos conteúdos e lhes deem significados para além da sala de aula.

Por isso, a importância da análise do currículo, tanto de seus conteúdos como de suas formas, é básica para entender a missão da instituição escolar em seus diferentes níveis e modalidades. As funções que o currículo cumpre como expressão do projeto de cultura e socialização são realizadas através de seus conteúdos, de seu formato e das práticas que cria em torno de si. (SACRISTÁN, 2000, p. 16)

Pensar uma prática diferente, requer também pensar uma formação diferente dos professores, responsáveis por articulá-la e executá-la.

Segundo Novoa (2007 p. 14),

A formação do professor é, por vezes, excessivamente teórica, outras vezes excessivamente metodológica, mas há um déficit de práticas, de refletir sobre as práticas, de trabalhar sobre as práticas, de saber como fazer. É desesperante ver certos professores que têm genuinamente uma enorme vontade de fazer de outro modo e não sabem como. Têm o corpo e a cabeça cheios de teoria, de livros, de teses, de autores, mas não sabem como aquilo tudo se transforma em prática, como aquilo tudo se organiza numa prática coerente.

Tendo em vista que muitas lacunas são deixadas na formação inicial dos professores, é necessário que se adote uma postura reflexiva para a construção de novos conhecimentos que serão reinvestidos na sua ação. Limitar-se na sua formação inicial é parar no tempo, é necessário estar em constante aperfeiçoamento para superar seus limites e transformar sua prática. 
Para Kleiman, (2005, p. 51), "O professor que acha que, no seu curso de formação, aprenderá tudo o que um dia poderá precisar para inserir seus alunos nas práticas letradas da sociedade é um professor fadado ao desapontamento."

Ainda segundo a autora, (pp. 51,52),

Para formar leitores, o professor, além de ser plenamente letrado, é claro, precisa ter os conhecimentos necessários para agir como um verdadeiro agente social. Ele tem de ser um gestor de recursos e de saberes — tanto dos dele (que talvez até nem saiba que possui porque deles nunca precisou) como dos de seus alunos.

É importante à prática docente que haja momentos de reflexão sobre a própria prática, a fim de se analisar os resultados obtidos através dela. Nas escolas esses momentos de reflexão nem sempre são propostos pelos professores, mas, na maioria das vezes, são programas de governo, dos quais os professores são obrigados a participar, chamados de formação continuada ou formação em serviço, nem sempre bem aceitas pelos professores, uma vez que não refletem seus anseios ou suas necessidades, o que gera desinteresse e desmotivação. Ao retornarem para as suas salas de aula, retornam a sua velha prática do dia a dia e não aplicam nada do que foi aprendido no curso de aperfeiçoamento, pois alegam que no currículo a ser cumprido não há tempo para que o conhecimento moderno seja aplicado.

Para que a prática docente produza resultados positivos, é necessário a que a formação continuada seja uma prática através da formação de grupos em que todos os envolvidos compartilhem suas necessidades, tomem decisões e busquem soluções, tornando-se responsáveis pela qualidade do que é produzido em conjunto, conforme suas possibilidades e interesses. Assim podem propor um currículo que atenda às necessidades dos alunos e que faça sentido a todos os envolvidos no processo do ensino e da aprendizagem.

\section{Referências}

BRASIL, Secretaria de Educação Fundamental. Parâmetros Curriculares Nacionais: língua portuguesa. Brasília: MEC/SEF, 1997.

Lei de Diretrizes e Bases da Educação Nacional - LDB Lei no 9394/96

BRITTO, Luiz Percival Leme. Contra o consenso: cultura escrita, educação e participação. Campinas: Mercado das Letras, 2003.

COLL, César. Psicologia e Currículo: uma aproximação psicopedagógica à elaboração do currículo escolar. 5 ed. São Paulo: Ática, 2003.

GUEDES, Paulo Coimbra. A formação do professor de português: que lingua vamos ensinar? São Paulo: Parábola Editorial, 2006. 
LIBÂNEO, J. C.; OLIVEIRA J. F.; TOSCHI M. S. Educação escolar: políticas estrutura e organização. $2^{a}$ ed. São Paulo: Cortez, 2005.

LIMA, Elvira Souza. Indagações sobre currículo: currículo e desenvolvimento humano. Organização do documento Jeanete Beauchamp, Sandra Denise Pagel, Aricélia Ribeiro do Nascimento. Brasília: Ministério da Educação, Secretaria de Educação Básica, 2007.

MARCUSCHI, L.A. Gêneros Textuais: definição e funcionalidades. In: Dionísio, A. et al. Gêneros textuais e ensino. São Paulo: Parábola Editorial, 2010.

MARCUSCHI, Luís Antônio. Da fala para a escrita: atividades de retextualização. 10 ed. São Paulo: Cortez, 2010.

MIZUKAMI, Maria da Graça Nicoletti. Ensino: as abordagens do processo. São Paulo: EPU, 1986.

NÓVOA, António. Desafios do trabalho do professor no mundo contemporâneo. São Paulo: Sindicato dos professores de São Paulo, 2007.

SACRISTÁN, J. Gimeno. O currículo: uma reflexão sobre a prática. 3.ed. Porto Alegre: Artmed, 2000.

SOARES, Magda. Letramento: um tema em três gêneros. 3. ed. Belo Horizonte: Autêntica, 2009.

TFOUNI, Leda Verdiani. Letramento E alfabetização. 9. ed. São Paulo: Cortez̧, 2010. 